\title{
List of major dates and events
}

1900 Ozaki Masutarō born in Kasama, July 1

1923 He becomes a Tenri missionary

1927 He marries

1928 Mrs. Sugihara comes to his mission in Osaka

1936 Ozaki Sensei begins smashing altars; Seki Iwazō declares war on Ozaki; the funeral of Imanishi Kunimatsu is held; police interrogate Sensei and others

1937 Ozaki and the four families are ostracized from Kasama

1938 Obatake house built; Sensei moves from Osaka to the Obatake house in Kasama; communal living begins for the four families

1940 Shinkyō donates two Imperial Shrines to schools

1943 First Shinkyō group emigrates to Manchuria; Ozaki and Mrs. Sugihara are divorced by their spouses

1944 Second Shinkyō team (children) emigrates to Manchuria

1945 Sensei and Mrs. Sugihara return to Kasama in January; both are jailed in August

1946 Emigrants return from Manchuria to Kasama

1947 Tatami-making begins at Shinkyō

1948 Tatami factory is built, destroyed by a typhoon, and rebuilt; Mrs. Sugihara suffers a nervous breakdown

1954 Shinkyō and Kasama consolidate with Haibara town

1957 Sensei becomes Chief of Kasama District

1959 He proclaims the new Eve celebration

1960 Tatami factory burns down and is rebuilt

1966 New and larger tatami factory is opened

I967 Shinkyō opens a home for retarded children 
